\title{
Arsenic trioxide induces gasdermin E mediated pyroptosis in astroglioma cells
}

\author{
Jingling Wang ${ }^{1}$, Linghui Zhan ${ }^{1}$, Zheng Cai ${ }^{1}$, Xiaomei Liu ${ }^{1}$, Junsheng Wang ${ }^{1}$, Huarong Zhong ${ }^{1}$, \\ Xianwei Huang ${ }^{2}$, Qinxiao Lai ${ }^{1}$, Qingzhao Tan ${ }^{1}$, Yibin Xiu ${ }^{1}$, Daowei Yang ${ }^{1}$, Xianghui Min ${ }^{1}$ \\ ${ }^{1}$ Department of Emergency, Zhongshan Hospital of Xiamen University, Xiamen 361005, China; ${ }^{2}$ Department of Emergency, First Hospital of \\ Xiamen University, Xiamen 361005, China \\ Contributions: (I) Conception and design: D Yang; (II) Administrative support: J Wang, D Yang; (III) Provision of study materials or patients: None; \\ (IV) Collection and assembly of data: J Wang, D Yang; (V) Data analysis and interpretation: D Yang; (VI) Manuscript writing: All authors; (VII) Final \\ approval of manuscript: All authors. \\ Correspondence to: Daowei Yang; Xianghui Min; Yibin Xiu. Department of Emergency, Zhongshan Hospital of Xiamen University, Xiamen 361005, \\ China. Email: dwyang@outlook.com; mxianghui@aliyun.com; 506123026@qq.com.
}

\begin{abstract}
Background: Arsenic trioxide (ATO) has been proved useful for the treatment of acute promyelocytic leukemia (APL). Apoptosis is the result of the cytotoxic effect of ATO, apoptotic mediated cell death confirmed by DNA fragmentation and Annexin V staining. Although signaling associated with ATO-induced apoptosis has been well defined, it is still unknown whether other forms of cell death are involved in ATOinduced cell death.
\end{abstract}

Methods: Western blotting, cytotoxicity assay, transmission electron microscopy were used to evaluate other forms of cell death in U251 cells.

Results: We found that pyroptotic mediated cell death was observed in U251 cells after ATO treatment, which was confirmed by observing the increased gasdermin E (GSDME) cleavage, lactate dehydrogenase $(\mathrm{LDH})$ release and transmission electron microscopy imaging. Consistent with previous results, caspase-3 was activated by ATO, which was also important for GSDME cleavage and subsequent pyroptosis.

Conclusions: We reported that GSDME mediated pyroptosis involved in ATO induced cell death in astroglioma cells.

Keywords: Arsenic trioxide (ATO); gasdermin E (GSDME); pyroptosis

Submitted Nov 28, 2019. Accepted for publication Feb 04, 2020.

doi: $10.21037 /$ tcr.2020.02.17

View this article at: http://dx.doi.org/10.21037/tcr.2020.02.17

\section{Introduction}

Arsenic trioxide (ATO) has been considered as an anticancer activity in various malignancies with a large body of mechanisms. In acute promyelocytic leukemia (APL), ATO is an effective therapeutic intervention to improve the patients' survival and remission (1). ATO could induce the degradation of PML-RAR $\alpha$ to result in terminal differentiation and apoptosis which may result from the Bcl-2 downregulation and cytochrome $c$ release (2). Recently, ATO was applied to the treatment of non-small cell lung cancer (NSCLC) by inducing cell cycle arrest (3).
Moreover, ATO could trigger DNA damage and apoptosis in glioma cells $(4,5)$.

Pyroptosis is a pro-inflammatory form of programmed cell death against pathogen infection, which is critical for the antimicrobial response (6). Prior results suggested pyroptosis was mainly observed in myeloid cells (7). Recent attention on the role of pyroptosis as a programmed cell death suggested that gasdermin E (GSDME)-mediated pyroptosis contributed to the toxicity of chemotherapy (8). Chemotherapy drugs could cause cancer cell cytotoxicity by activating caspase-3-mediated cleavage of GSMDE (9). 
More recently, it was reported that iron could activate reactive oxygen species (ROS) to trigger GSDME-mediated pyroptosis in melanoma cells (10).

ATO has been verified to attenuate the proliferation of glioblastoma cells through apoptosis (11). However, no evidence shows that GSDME-mediated pyroptosis is involved in ATO-induced cell death in glioblastoma cells. In the present study, we found that GSDME mediated pyroptosis took part in ATO induced cell death in astroglioma cells.

\section{Methods}

\section{Cell culture and reagents}

U251 cells were obtained from ATCC. All cells were cultured in Dulbecco's modified Eagle's medium (DMEM) supplemented with $10 \%$ fetal bovine serum (FBS) and nonessential amino acids, $100 \mathrm{IU}$ penicillin and $100 \mathrm{mg} / \mathrm{mL}$ streptomycin at $37^{\circ} \mathrm{C}$ in a humidified incubator containing $5 \% \mathrm{CO}_{2}$. GSDME antibody (ab215191) was obtained from Abcam. Caspase-3 antibody (9662S) was from Cell Signaling Technology. LaminB1 antibody (66095-1-Ig) was from Proteintech.

\section{Cytotoxicity assay}

LDH assay using CytoTox 96 Non-Radioactive Cytotoxicity Assay kit from Promega Corporation to measure cell viability and cell lysis according to the manufacturer's instructions.

\section{Immunoblotting}

Western blotting was performed as previously described (12). Proteins were separated by SDS-PAGE and transferred to PVDF membrane. The membrane was blocked and incubated at $4{ }^{\circ} \mathrm{C}$ overnight with indicated first antibodies, followed by incubation with corresponding HRP-conjugated secondary antibodies. The protein bands were detected with an ECL. The luminescent signals of immunoblotting were analyzed by using an ImageQuan LAS 4000 Scanner (GE Healthcare).

\section{Transmission electron microscopy}

U251 cells were fixed with $2.5 \%(\mathrm{v} / \mathrm{v})$ glutaraldehyde after stimulation with DMSO or ATO. The sample was prepared according to the standard protocol, and the cells' morphology was observed with JEOL JEM21OOHC transmission electron microscopy.

\section{Statistical analysis}

All results are analyzed using the GraphPad 6.0 software and expressed as means \pm standard error of the mean (SEM). The analysis was performed by two-tailed unpaired Student's $t$-test and $\mathrm{P}<0.05$ was considered statistically significant.

\section{Results}

\section{GSDME was cleaved in the process of ATO treatment in U251 cells}

To test whether GSDME was activated during the stimulation of ATO in U251 cells, GSDME protein level was assessed by Western blot, as it was suggested that GSDME was highly expressed in U251 cells (Figure 1). GSDME was reported to be cleaved by caspase-3 during chemotherapy drug treatment. We then tested whether GSDME in U251 cells was cleaved upon ATO treatment. As shown in Figure 1, GSDME was cleaved into two fragments in U25 1 cells stimulated with increasing concentrations of ATO for $24 \mathrm{~h}$.

\section{Caspase-3 was activated after ATO stimulation}

Recently, it was reported that activated caspase-3 could cleaved GSDME to execute pyroptosis. To confirm caspase- 3 was activated by ATO in U251 cells, cleaved caspase- 3 was detected through immunoblotting. As expected, caspase-3 was processed to an active form after ATO exposure (Figure 2). Thus, these results indicated that caspase- 3 was activated during ATO-induced cell death in U251 cells.

\section{LDH release was observed in the process of ATO-induced cell death}

Prior reports suggested that LDH release was the specific marker for pyroptosis. To study whether LDH release occurred in the process of ATO stimulation, the level of LDH in the supernatant medium was monitored. As 

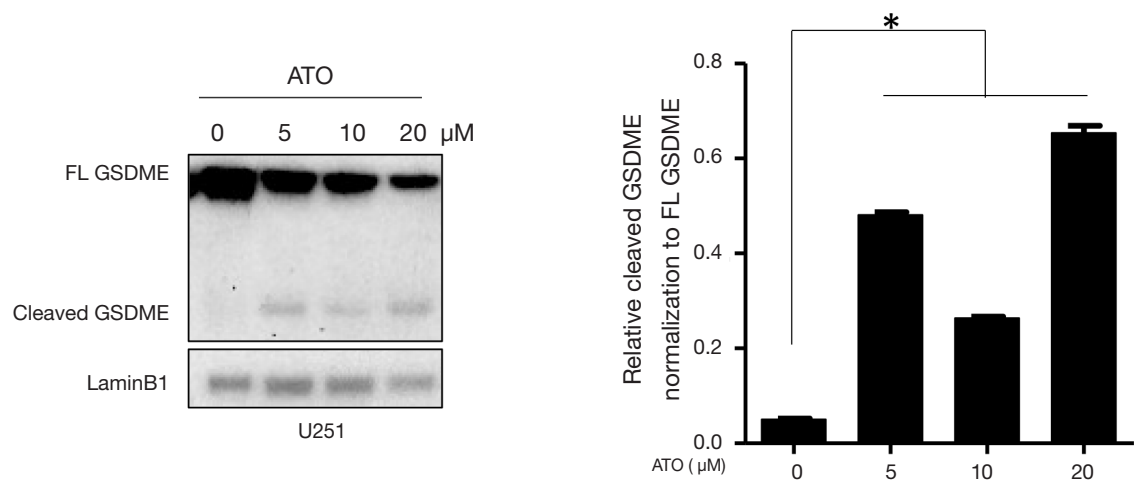

Figure 1 U251 cells were treated for $24 \mathrm{~h}$ with increasing concentration of ATO. The cells were lysed and immunoblotted with the indicated antibodies. The full-length GSDME was shown as FL in the figure. Results are representative of two independent experiments. *, $\mathrm{P}<0.05$. Data are presented as mean \pm SEM and analyzed with a two-tailed unpaired Student's $t$-test. ATO, arsenic trioxide; FL, full-length; GSDME, gasdermin E; SEM, standard error of the mean.
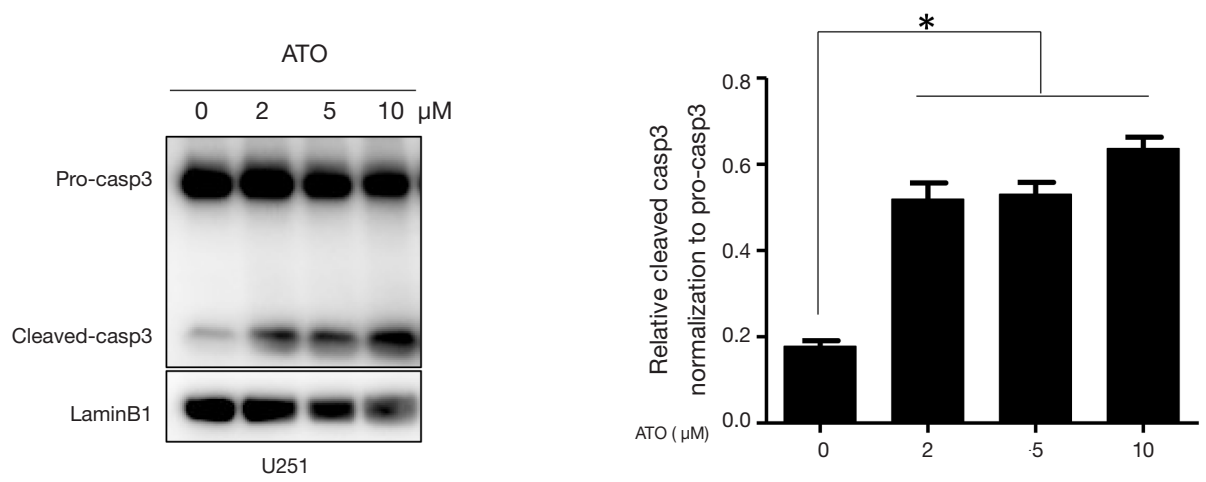

Figure 2 U251 cells were treated for $24 \mathrm{~h}$ with increasing amounts of ATO. The cells were lysed and immunoblotted with the indicated antibodies. Results are representative of two independent experiments. * $\mathrm{P}<0.05$. Data are presented as mean \pm SEM and analyzed with a two-tailed unpaired Student's $t$-test. ATO, arsenic trioxide; SEM, standard error of the mean.

anticipated, we were able to observe the marked release of LDH in U251 cells after exposure to ATO treatment (Figure 3). Therefore, the administration of ATO for $24 \mathrm{~h}$ could initiate the significant release of $\mathrm{LDH}$, indicating the integrity of the plasma membrane was disrupted and pyroptosis occurred.

\section{U251 treated with ATO was characterized by the rupture of the plasma membrane and cytoplasmic swelling}

To further verify the cell death induced by ATO was pyroptosis, the morphologies of the ATO-induced cell death in U251 cells were analyzed through the transmission electronic microscopy (TEM). Indeed, U251 treated with ATO was characterized by the rupture of the plasma membrane and cytoplasmic swelling (Figure 4). Thus, these data confirmed that ATO stimulation can result in pyroptosis in $\mathrm{U} 251$ cells.

\section{Discussion}

ATO has been considered an environmental carcinogen. Until the last decade, it is explored as an anticancer drug for APL. While many research results focus on how ATO kills malignant myeloid cells through terminal differentiation and apoptosis, few reports have examined the role of other 


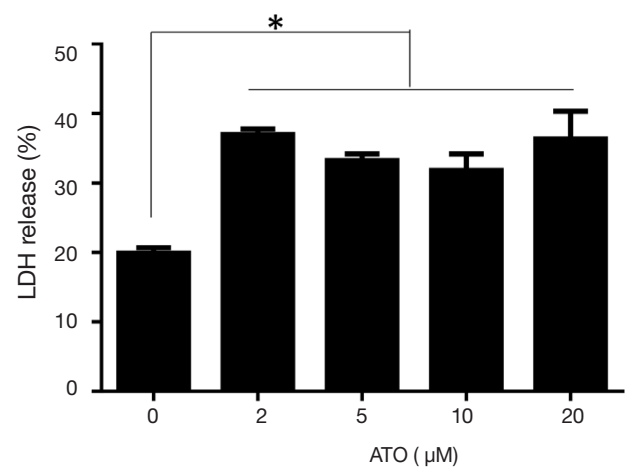

Figure 3 U251 cells were treated for $24 \mathrm{~h}$ with increasing concentration of ATO. The LDH from the supernatant was measured according to the manufacturer's instructions. Data are means \pm SEM of three independent experiments. *, $\mathrm{P}<0.05$, by two-tailed unpaired Student's $t$-test. ATO, arsenic trioxide; LDH, lactate dehydrogenase; SEM, standard error of the mean.
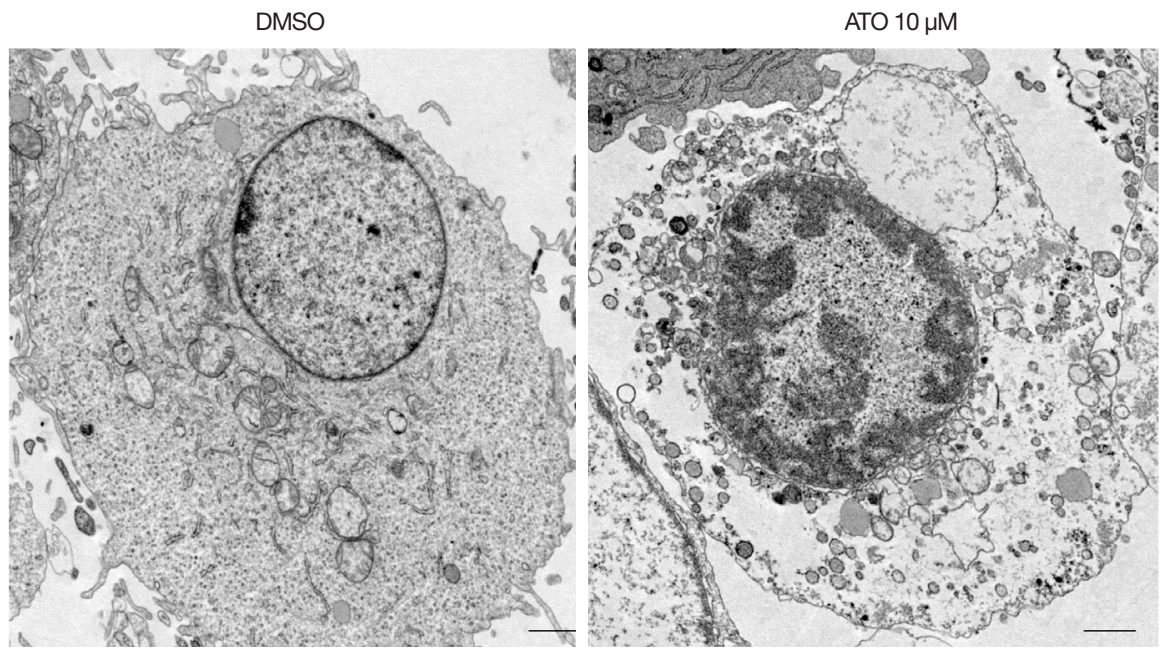

Figure 4 The morphology of U251 cells treated with DMSO or $10 \mu \mathrm{M}$ ATO for $24 \mathrm{~h}$, then these cells were analyzed by transmission electron microscopy and the representative image was shown. Scar bar, $2 \mu \mathrm{m}$. ATO, arsenic trioxide.

forms of cell death that are implicated in tumor cells after exposure to ATO.

In this study, we investigated ATO could induce pyroptosis in U251 cells. Although it is unknown whether pyroptosis plays a pivotal role in the treatment of APL and multiple myeloma using ATO. To better define the role of pyroptosis in ATO-induced growth inhibition in lymphoid and myeloid malignant cells, the experiment of xenograft tumor with or without GSDME expression in athymic mice needs to be established for further investigation.
Finally, our study markedly promotes the understanding of molecular mechanisms governing ATO-induced cell death. Pyroptosis may be important for developing new approaches for the combination therapy with ATO.

\section{Acknowledgments}

Funding: This work was supported by grants from the Natural science foundation of Fujian province (No. 2019J01559) and the National Natural Science Foundation of China (No. 81671583). 


\section{Footnote}

Conflicts of Interest: All authors have completed the ICMJE uniform disclosure form (available at http://dx.doi. org/10.21037/tcr.2020.02.17). The authors have no conflicts of interest to declare.

Ethical Statement: The authors are accountable for all aspects of the work in ensuring that questions related to the accuracy or integrity of any part of the work are appropriately investigated and resolved. The study was conducted in accordance with the Declaration of Helsinki (as revised in 2013). Informed consent was waived. This study was approved by the ethics committee of Zhongshan Hospital of Xiamen University (No. XMZSYY-AFSC-02-03).

Open Access Statement: This is an Open Access article distributed in accordance with the Creative Commons Attribution-NonCommercial-NoDerivs 4.0 International License (CC BY-NC-ND 4.0), which permits the noncommercial replication and distribution of the article with the strict proviso that no changes or edits are made and the original work is properly cited (including links to both the formal publication through the relevant DOI and the license). See: https://creativecommons.org/licenses/by-nc-nd/4.0/.

\section{References}

1. Chen GQ, Shi XG, Tang W, et al. Use of arsenic trioxide (As2O3) in the treatment of acute promyelocytic leukemia (APL): I. As2O3 exerts dose-dependent dual effects on APL cells. Blood 1997;89:3345-53.

2. Wang ZY, Chen Z. Acute promyelocytic leukemia: from highly fatal to highly curable. Blood 2008;111:2505-15.

Cite this article as: Wang J, Zhan L, Cai Z, Liu X, Wang J, Zhong H, Huang X, Lai Q, Tan Q, Xiu Y, Yang D, Min X. Arsenic trioxide induces Gasdermin E mediated pyroptosis in astroglioma cells. Transl Cancer Res 2020;9(3):1926-1930. doi: 10.21037/tcr.2020.02.17
3. Zheng CY, Lam SK, Li YY, et al. Arsenic trioxide-induced cytotoxicity in small cell lung cancer via altered redox homeostasis and mitochondrial integrity. Int J Oncol 2015;46:1067-78.

4. Cheng Y, Li Y, Ma C, et al. Arsenic trioxide inhibits glioma cell growth through induction of telomerase displacement and telomere dysfunction. Oncotarget 2016;7:12682-92.

5. Wang J, Li Y, Jiang C. MiR-133b contributes to arsenicinduced apoptosis in U251 glioma cells by targeting the hERG channel. J Mol Neurosci 2015;55:985-94.

6. Jorgensen I, Miao EA. Pyroptotic cell death defends against intracellular pathogens. Immunol Rev 2015;265:130-42.

7. Robinson N, Ganesan R, Hegedus C, et al. Programmed necrotic cell death of macrophages: Focus on pyroptosis, necroptosis, and parthanatos. Redox Biol 2019;26:101239.

8. Wang Y, Gao W, Shi X, et al. Chemotherapy drugs induce pyroptosis through caspase-3 cleavage of a gasdermin. Nature 2017;547:99-103.

9. Zhang CC, Li CG, Wang YF, et al. Chemotherapeutic paclitaxel and cisplatin differentially induce pyroptosis in A549 lung cancer cells via caspase-3/GSDME activation. Apoptosis 2019;24:312-25.

10. Zhou B, Zhang JY, Liu XS, et al. Tom20 senses ironactivated ROS signaling to promote melanoma cell pyroptosis. Cell Res 2018;28:1171-85.

11. Ghaffari SH, Yousefi M, Dizaji MZ, et al. Arsenic Trioxide Induces Apoptosis and Incapacitates Proliferation and Invasive Properties of U87MG Glioblastoma Cells through a Possible NF-kappaB-Mediated Mechanism. Asian Pac J Cancer Prev 2016;17:1553-64.

12. Yang D, Liang $\mathrm{Y}$, Zhao S, et al. ZBP1 mediates interferoninduced necroptosis. Cell Mol Immunol 2019. [Epub ahead of print]. 